\title{
Knowledge sharing in alliances and alliance portfolios*
}

\author{
Ashish Arora $^{\dagger} \quad$ Sharon Belenzon ${ }^{\ddagger} \quad$ Andrea Patacconi ${ }^{\S}$
}

January 24,2020

\begin{abstract}
We develop a model of knowledge sharing in alliances and alliance portfolios. We show that once the issue of encouraging effective collaboration is put center-stage, many standard intuitions of the learning race view and alliance portfolio literature are overturned or qualified. Partners engage in learning races in some cases, but exhibit 'altruistic' behaviors in other cases. They may reduce their own absorptive capacity, or increase the transparency of their own operations, to facilitate their partner's learning. In alliance portfolios, we show that not all substitutability between alliance portfolio partners is bad. We distinguish between substitutability in implementation and substitutability in rival benefits, and show that the latter is conducive to knowledge sharing. Our work contributes towards putting the literature on learning alliances on a more solid foundation by emphasizing the importance of commitments that leading firms can make to encourage collaboration.
\end{abstract}

Keywords: knowledge sharing, learning alliances, alliance portfolios, commitment, learning races.

JEL Classification: D21, D23, L24.

\section{Introduction}

Learning alliances, where an important objective of the partners is the creation of new knowledge, are difficult to manage. On the one hand, the partnering firms (who may also be competitors) must share knowledge to create new knowledge, and cooperatively exploit this jointly created new knowledge (Hennart, 1988; Mitchell and Singh, 1996). This gives them a common purpose. On the other hand, the partners must divide the gains from collaboration. The negotiations are affected by the relative bargaining positions after sharing, which depend upon how efficiently firms have learned from each other, and how well positioned they are to exploit that learning without the cooperation of the partner (Hamel, 1991; Yan and Gray, 1994; Panico, 2017).

\footnotetext{
${ }^{*}$ We would like to thank Catherine de Fontenay, Nick Vikander, numerous seminar partecipants and especially the Editors and the Reviewers for very constructive feedback and criticism. All remaining errors are of course ours.

${ }^{\dagger}$ Fuqua School of Business, Duke University, and NBER. Email: ashish.arora@duke.edu

${ }^{\ddagger}$ Fuqua School of Business, Duke University, and NBER. Email: sharon.belenzon@duke.edu

$\S^{\S}$ Norwich Business School, University of East Anglia. Email: A.Patacconi@uea.ac.uk
} 
In many cases, the new knowledge created cannot be accurately foreseen nor adequately distinguished from what is already known by the partners. Thus, firms cannot contract or commit to jointly exploit it. Any existing contract or joint venture terms are subject to renegotiation under the threat that one partner or the other may walk away (Williamson, 1975; Grossman and Hart, 1986). As a result, firms may be reluctant to collaborate and share knowledge ex ante, if they expect to find themselves in a weak bargaining position ex post.

Consider for instance the alliance between Nypro and Vistakon, a division of Johnson \& Johnson (Christensen, 1994). The goal of this alliance was to develop single-use lens' molds for disposable contact lenses. While the project required substantial joint problem-solving, conflicts arose when attempts were made to more fully integrate the two firms' engineering teams. Senior managers at Nypro opposed these attempts, on the ground that they could compromise Nypro's intellectual property and bargaining position. Christensen highlights three key concerns. First, Nypro managers noted that although Nypro held several patents, much of its technology was not patented, as it involved process innovations that were best protected through trade secrets. One concern was that Vistakon engineers, after learning trade secrets from Nypro, could take jobs with injection molders directly competing with Nypro. A second concern was that Vistakon could use this information to develop alternative technologies to making lenses, which Vistakon was free to explore in parallel with its program with Nypro. Third, Nypro worried that, if the project was successful, Vistakon could use its better understanding of Nypro's manufacturing process to constrain Nypro's pricing flexibility and bargaining power in future supply contracts. For these reasons, knowledge sharing with Vistakon had to be managed carefully, and sometimes constrained.

Naturally alliance partners may attempt to mitigate such risks from knowledge sharing. Much of the literature focuses on defence mechanisms that firms can use to protect their knowledge from expropriation (e.g., Cohen et al., 2000; Katila et al., 2008). Here we take a complementary perspective and study organizational commitments that leading firms can use to encourage knowledge sharing when appropriability hazards are present (Schelling, 1960; Williamson, 1983). Nypro was concerned that sharing its knowledge, though vital to the success of the alliance, would hurt its bargaining position in the alliance. Therefore, if Vistakon could commit not to take advantage of Nypro, the latter would be more likely to share knowledge.

Our focus on commitments to encourage knowledge sharing yields recommendations that are often very different from, and sometimes diametrically opposed to, what some strategic management approaches suggest. A key tenet of the learning race literature (Hamel, 1991; Yan and Gray, 1994; Inkpen and 
Beamish, 1997; Khanna et al., 1998) is that alliance partners should "maximize their receptivity to the knowledge and skills of their partner while limiting the transparency of their own operations" (Mowery et al., 2002: 298). In our framework, firms engage in "learning races" in some cases but exhibit "altruistic" behaviors in other cases. This may help explain some apparently puzzling behaviors, such as Toyota's willingness to teach lean manufacturing to GM, a competitor (Inkpen, 2005). It may also help explain why sometimes firms such as Intel, Toyota, and Cisco appear to deliberately reduce their own learning capability through internal "Chinese walls" (Gawer and Cusumano, 2002; Dyer and Nobeoka, 2000; Steinhilber, 2008). ${ }^{1}$

Leading firms may also commit to low appropriation of a partner's knowledge by creating alliance portfolios with desirable characteristics. Existing research suggests that synergies between partners encourage collaboration, while partner substitutability hinders it by exacerbating competitive tensions (McEvily et al., 2000; Bae and Gargiulo, 2004; Lavie, 2007). However, empirical work on the effects of partner substitutability or similarity has yielded largely inconclusive results (Goerzen and Beamish, 2005; Swaminathan and Moorman, 2009; Vasudeva and Anand, 2011; Cui and O'Connor, 2012; Cui, 2013).

We provide a potential explanation for these mixed results by distinguishing between two types of partner substitutability: substitutability in implementation and substitutability in rival benefits. Substitutability in implementation refers to situations where the contribution of a former partner $A$ to the implementation of a project can partly be replaced by the contribution of a staying partner B. Because this type of substitutability makes it easier for the focal firm, $F$, to first appropriate $A$ 's knowledge and then terminate the alliance with $A, A$ 's incentives to share knowledge are reduced. Thus, substitutability in implementation hinders knowledge sharing.

Substitutability in rival benefits, by contrast, refers to a situation where the focal firm $F$ does not gain much by appropriating the knowledge of both $A$ and $B$, relative to appropriating the knowledge of only $A$ or $B$. Intuitively, if $A$ and $B$ 's knowledge bases overlap significantly, the marginal returns to appropriating partners' knowledge may be decreasing. In this case, although knowledge sharing in a single alliance may be unfeasible, we show that knowledge sharing in a portfolio (with both $A$ and $B$ ) can be feasible.

A second implication of our analysis that a focal firm $F$ is often better off by choosing partners that are neither too similar nor too dissimilar to each other. This is because partner substitutability (both

\footnotetext{
${ }^{1}$ Our focus on knowledge sharing also yields the counter-intuitive result that uncertainty about outcomes need not always hinder knowledge sharing. Instead, greater uncertainty (in the form of mean preserving spreads) or even asymmetric information may actually facilitate knowledge sharing.
} 
in implementation and rival benefits) affects in opposite ways the probability of knowledge sharing and the share of value captured by the focal firm. Thus, as suggested by some recent studies (Swaminathan and Moorman, 2009; Vasudeva and Anand, 2011), the relationship between alliance value and partner substitutability may first increase and then decline.

This paper makes two main contributions. First, by emphasizing the need to encourage knowledge sharing, we contribute toward putting the literature on learning alliances on a more solid foundation. Scholars have noted that many of the learning race view's recommendations suffer from a failure to recognize that the processes of value creation and value appropriation are inextricably linked (e.g., Zeng and Hennart, 2002). Some have also argued that the notion of a race to learn is "largely unrealistic", for it is unclear what would motivate a likely loser to join the race (Inkpen, 2002: 272). This paper incorporates a knowledge sharing constraint into a model of learning in alliances, and shows that its inclusion has important consequences for how alliances should be managed. In particular, the model may help explain why, although learning is an important goal in many alliances, only few firms actually appear to have a racing intent (Mowery et al., 1996; Hennart et al., 1999; Inkpen, 2000).

The second main contribution of the paper is to re-orient attention in strategy and economics from the problem of how firms can protect their intellectual assets (e.g., Cohen et al., 2000; Katila et al., 2008), to the problem of how leading firms can promote the health of their innovation ecosystems. Iansiti and Levien (2004) distinguish between "keystone organizations", which share the benefits from collaboration with their partners, and "physical dominators", which focus on value appropriation. We examine how keystone organizations can use commitment to help create ecosystems conducive to knowledge sharing and innovation.

\section{$1.1 \quad$ Related literature}

This paper is related to several strands of the literature on alliances. By emphasizing contractual incompleteness and ex ante investment incentives, our model builds on the property-rights view of the firm. This literature studies how property rights should be allocated when concerns about hold-up reduce partners' investment incentives (Grossman and Hart, 1986; Hart and Moore, 1990). A key insight of this literature is that, to maximize ex ante efficiency, property rights should be assigned to the party whose investment matters most to joint value creation. Aghion and Tirole (1994), however, point out that an optimal allocation of property rights may not be achieved if one of the partners is cash constrained. Panico (2017) argues that ownership structures that give partners strong incentives to create value may also give them 
strong incentives to engage in value appropriation. He studies how different ownership structures affect value creation and appropriation when partners interact only once or repeatedly. This paper develops a model where partners' investments are equally costly and important; hence, an equitable division of the gains from collaboration tends to promote investment. ${ }^{2}$ The problem we emphasize is that investment may alter the partners' bargaining positions (i.e., their outside options). ${ }^{3}$

A few papers examine how shifts in bargaining positions affect investment incentives. Nicita and Sepe (2012) note that, when investment affects outside options, overinvestment as well as underinvestment can occur. de Fontenay and Gans (2005), Patacconi and Vikander (2015) and Herbst and Walz (2017) explore in different settings the idea that bargaining with other potential partners determines each firm's outside option. We focus on organizational commitments to encourage investment. The commitments we emphasize are constraints to one's own absorptive capacity and alliance portfolio design. Panico (2017) examines incentives to invest in value appropriation, which could be interpreted as investments in absorptive capacity. However, in Panico's model, investments in value appropriation and investments in value capture are chosen simultaneously. Commitment, on the other hand, requires a sequential choice. ${ }^{4,5}$

The commitments that have been more extensively studied in economics are contractual or equitybased (e.g., Williamson, 1983; Oxley, 1997). Williamson (1983) considers a model where producers can make relationship-specific investments but such investments create the potential for hold-up. He shows that, under some conditions, efficient contracting can be achieved if the buyer posts a 'hostage' (such as a termination fee) that is delivered to the producer if the order is cancelled. Equity alliances (those involving the sharing or exchange of equity) can also be conceptualized as commitments. These structures embody complex administrative structures that enhance control over technology flows and facilitate collaboration (Pisano, 1989; Oxley and Wada, 2009). In Section 5, we conclude that, although these contractual solutions ameliorate the problem of shifting bargaining positions, they only ensure

\footnotetext{
${ }^{2}$ Such balanced division may result from an equitable allocation of property rights, as in Panico's (2017) case of 'symmetric control', or from negotiations between a monopsonistic customers and the owner of an innovation, as in Aghion and Tirole's (1994) case of 'RU-ownership'.

${ }^{3}$ Most of the property-rights literature assumes that asset ownership, but not investment, affects partners' outside options.

${ }^{4}$ Panico (2011) develops a model where a focal firm selects prior to investment both the fraction of property rights and the fraction of control rights assigned to each partner. Property rights affect the partners' outside options, while control rights affects how the surplus from collaboration is divided between the partners. Panico finds that, in equilibrium, ownership and control rights are often substitutes. We obtain a similar result in Section 5, where we consider equity alliances. However, in addition to contractual solutions, our paper also considers organizational commitments (restrictions to one's own absorptive capacity and alliance portfolio design).

${ }^{5}$ This paper is also related to the biform approach used in the literature on value creation and capture (e.g., Brandenburger and Stuart, 2007; Ryall and Sorenson, 2007). In our model, commitments and investments inknowledge sharing occur sequentially in the first noncooperative stage, and payoffs results from negotiations in the second cooperative stage.
} 
efficiency under stringent conditions. Thus, organizational commitments remain important. ${ }^{6}$

We focus on learning alliances and investments in knowledge sharing. Our analysis is motivated by the observation that knowledge sharing often alters the partners' bargaining positions through knowledge spillovers. Information leakage and knowledge misappropriation are often cited as a major drawbacks of R\&D collaborations (Veugelers and Kesteloot, 1994; Arora and Merges, 2004; Katila et al., 2008). ${ }^{7}$ Knowledge sharing can also shift the balance of power in favor of the alliance partner that learns the fastest, potentially giving rise to "learning races" and instabilities (Hamel, 1991; Yan and Gray, 1994; Inkpen and Beamish, 1997).

The literature has largely focused on how firms can protect themselves against their knowledge spillovers in alliances. Katila et al. (2008), for instance, find that startups are more likely to enter corporate investment relationships with incumbents when they can defend themselves against misappropriation. Defence mechanisms include not only patents and secrecy (Cohen et al., 2000), but also the selection of partners with limited opportunistic intent (Khanna et al., 1998; Baum et al., 2000; Dussauge et al., 2000). How leading firms can use commitments to encourage knowledge sharing within their ecosystems has been much less extensively studied. Our contribution is to show that incorporating ex ante knowledge sharing considerations in a model of learning alliances has important implications for alliance management.

Finally, our alliance portfolio design analysis is related to a growing literature examining how network structure affects knowledge sharing (Hansen, 2002; Argote et al., 2003; Reagans and McEvily, 2003). The similarity of knowledge sources within a network is often regarded as an obstacle to effective knowledge sharing, both because it reduces knowledge variety and because it creates competitive tensions (e.g., Baum et al., 2000). However, empirical findings have been mixed (e.g., Goerzen and Beamish, 2005; Swaminathan and Moorman, 2009; Cui 2013). Our work may help reconcile these mixed findings by highlighting a type of knowledge redundancy (substitutability in rival benefits) that can actually facilitate knowledge sharing.

The rest of the paper is organized as follows. The basic model is presented in Section 2. There we show that shifts in bargaining positions can destabilize alliances. Section 2.1 examines how uncertainty and different types of uncertainty resolution affect knowledge sharing. Subsequent sections focus on

\footnotetext{
${ }^{6}$ Our analysis focuses only on a few specific contracts; other contracts may perform better. See Segal and Whinston (2013) for a discussion of when/how contracts can ameliorate the hold-up problem.

${ }^{7}$ Veugelers and Kesteloot $(1994,1996)$ examine how knowledge spillovers between partners affect the stability of alliances. While these models capture the idea that knowledge spillovers undermine alliance stability, they do not investigate the role of commitments in facilitating knowledge sharing ex ante.
} 
commitments to facilitate knowledge sharing. Specifically, we examine: investments in absorptive capacity (Section 3), alliance portfolio design (Section 4), and contracts (Section 5). Section 6 concludes. Proofs are relegated to the online appendix.

\section{Model}

There are two firms, $F$ and $A$, that participate in an alliance or collaboration. We will sometimes refer to $F$ as the focal firm, because it may be involved in more than one alliance.

In period 0 (the commitment stage), the firms take actions that influence how their payoffs in future periods will evolve. We postpone the discussion of these actions (which in some cases can be interpreted as commitments) to Sections 3 to 5 . For now, we assume that no actions or commitments are available in period 0 .

In period 1 (the knowledge sharing stage), the firms simultaneously and noncooperatively choose whether to invest in knowledge sharing. We assume that these investments are not contractible. For instance, in the Nypro-Vistakon example discussed in the introduction, investments in knowledge sharing would involve a more extensive integration between the two firms' engineering teams than actually carried out. We assume that, if the firms invest in knowledge sharing, then each of them incurs a private cost $\frac{1}{2} I>0$. Thus, $I$ denotes the total cost associated with knowledge sharing. ${ }^{8}$

If $F$ and $A$ do not invest, then knowledge sharing costs are not incurred and $F$ and $A$ obtain their "baseline" payoffs, which we normalize to zero. These payoffs may correspond to either if the alliance is not formed or where an alliance is in place, but appropriability hazards prevent high levels of knowledge sharing, as in the Nypro-Vistakon example. Thus, a payoff of zero may describe a situation where $F$ and $A$ introduce a new product together, but the new product is not valuable, because of limited knowledge sharing. If both firms invest in knowledge sharing, then payoffs $V, \pi_{F}$ and $\pi_{A}$ are realized, where $V$ is the value of the alliance and $\pi_{F}$ and $\pi_{A}$ are, respectively, $F$ and $A$ 's (ex post) outside options. We assume that there is no uncertainty about $V, \pi_{F}$ and $\pi_{A}$. In Section 2.1, however, introduce uncertainty and both the case of symmetric resolution of uncertainty (both firms learn the same information) and asymmetric resolution of uncertainty (the firms learn different information) in period 2 (the uncertainty resolution stage).

In period 3 (the negotiation stage), the firms choose whether to continue to work together and earn $V$, or exit and obtain their outside options. If they continue to work together (i.e., they implement their

\footnotetext{
${ }^{8}$ The assumption that knowledge sharing costs $\frac{1}{2} I$ are the same for $F$ and $A$ is just for simplicity. This assumption could easily be relaxed without changing any of the qualitative results of the paper.
} 
project), then they must bargain over how to divide $V$. In the case of Nypro and Vistakon, implementation means developing new disposable contact lenses together, and sharing the profits from this new product. If instead $F$ and $A$ terminate their collaboration prematurely (before implementation), then $F$ gets $\pi_{F}$ and $A$ gets $\pi_{A}$. We allow $\pi_{F}$ and $\pi_{A}$ to differ from zero (the baseline payoffs in the absence of knowledge sharing) because knowledge sharing may affect the firms' competitive positions. For instance, $\pi_{F}$ and $\pi_{A}$ may both be positive if both $F$ and $A$ learn something useful from their interaction that allows them to improve their existing products, though of course one partner may learn more than the other (e.g., $\pi_{F}>\pi_{A}$ ). However, it could also be that one partner is "expropriated" by the other (e.g., $\pi_{F}>0$, $\left.\pi_{A} \leq 0\right)$. This is the "swimming with sharks" or "information leakage" scenario highlighted by many scholars (e.g., Veugelers and Kesteloot, 1994; Katila et al., 2008).

In the Nypro-Vistakon example, the risk that unwanted knowledge spillovers may help Vistakon develop alternative technologies to making lenses implies that $\pi_{F}>0$ (here $F$ stands for Vistakon and $A$ stands for Nypro). ${ }^{9}$ Similarly, the concern that Vistakon's better understanding of Nypro's manufacturing process could constrain Nypro's pricing flexibility and bargaining power in future supply contracts implies that $\pi_{F}>0$ or $\pi_{A}<0$. As we shall see, even if the partners end up jointly implementing the innovation, the ex-post outside options $\pi_{F}$ and $\pi_{A}$ affect how $F$ and $A$ share their joint value $V$.

Note that $\pi_{F}$ and $\pi_{A}$ only accrue if the collaboration is prematurely terminated. Indeed, to the extent that firm $F$ can use the knowledge it gains from the alliance without jeopardizing the alliance itself, these payoffs would simply be added to both $V$ and $\pi_{F}$, making the collaboration more attractive to $F$ without making it less attractive to $A$. Our interest, on the other hand, is in "rival benefits" which can potentially jeopardize the collaboration by making it less attractive to the other partner. In terms of our example, Vistakon would only develop alternative technologies to making lenses if its collaboration with Nypro was terminated. This outside option (worth $\pi_{F}$ ) would only be used if their joint project (worth $V$ ) was not completed. Nevertheless, because Vistakon could terminate the collaboration and still develop an alternative technology influenced how the value of the joint project $V$ was divided.

The key assumptions we make are that (i) it is impossible to contract on knowledge sharing, and that (ii) the firms cannot commit ex ante (before knowledge sharing) to implement the project together ex post. These assumptions imply that the firms cannot be forced to collaborate; neither in the initial phase of knowledge sharing nor in the subsequent implementation phase. This could be because it is impossible for a court to verify, for instance, that a firm has done its best to transmit its knowledge, or that a partner

\footnotetext{
${ }^{9}$ It could also be that $\pi_{A}<0$ if the development of these alternative technologies weakens Nypro's competitive position in the marketplace.
} 
is performing in a consummate rather than perfunctory fashion during co-development. In countries with less developed institutions, these assumptions may also reflect very high costs of using the legal system.

Note that firms will not unilaterally share knowledge. We assume that, if $F$ shares knowledge with $A$ but $A$ does not, then $F$ pays the knowledge sharing cost $\frac{1}{2} I$ and $A$ enjoys a benefit $\pi_{A}^{u} \geq 0$ (the superscript $u$ stands for unilateral knowledge sharing). If $A$ shares knowledge but $F$ does not, then $A$ pays the cost $\frac{1}{2} I$ and $F$ enjoys a benefit $\pi_{F}^{u} \geq 0$. Because knowledge sharing is not contractible, neither $F$ nor $A$ will unilaterally share its knowledge. Figure 1 summarizes the sequence of events.

\section{[Figure 1 about here]}

In period 3, if the firms share knowledge and implement their project together, they must bargain over the division of the surplus. We posit $V \geq \pi_{F}+\pi_{A}$. That is, after knowledge sharing, it is efficient for $F$ and $A$ to implement their project together. This could be because the partners have complementary capabilities in developing and commercializing the new product, or because competition following a breakup dissipate rents. We assume bargaining is efficient and determined according to the Nash solution with equal weights. Thus, the partners' payoff are given by

$$
\Pi_{i}=\pi_{i}+\frac{1}{2}\left[V-\pi_{F}-\pi_{A}\right]-\frac{1}{2} I, \quad i=F, A .
$$

That is, each firm gets its ex post (after knowledge sharing) outside option $\pi_{i}$, plus half of the surplus from implementation $V-\pi_{F}-\pi_{A}$, minus the costs of knowledge sharing $\frac{1}{2} I$. Knowledge sharing is efficient if $V \geq I$.

In a non-cooperative equilibrium, knowledge sharing occurs only if each firm $i=F, A$ obtains more when they both share knowledge than when they do not share knowledge:

$$
\Pi_{i} \geq 0
$$

We refer to (2) as $i$ 's knowledge sharing constraint. If this constraint holds, we say that knowledge sharing is privately profitable for firm $i$ (assuming that the other firm also shares knowledge). After some manipulations, $F$ and $A$ 's knowledge sharing constraints can be rewritten as:

$$
\begin{aligned}
& V-I \geq \pi_{A}-\pi_{F} \\
& V-I \geq \pi_{F}-\pi_{A}
\end{aligned}
$$


Unsurprisingly, $F$ and $A$ are more likely to collaborate if knowledge sharing creates substantial value $(V-I$ large). However, partners also care about their relative bargaining positions. If $\pi_{A}>\pi_{F}$, then knowledge sharing shifts bargaining power in favor of $A$ (that is, outside options shift from $(0,0)$ to $\left(\pi_{F}, \pi_{A}\right)$, with $\pi_{A}>\pi_{F}$ ), which makes $F$ less likely to share its knowledge (i.e., condition (3) is less likely to hold). Conversely, if $\pi_{F}>\pi_{A}$, then bargaining power shifts in favor of $F$, and $A$ is less likely to share knowledge with $F$. Conditions (3) and (4) make clear that both firms will invest only if $V-I \geq\left|\pi_{F}-\pi_{A}\right| \cdot{ }^{10}$ Note that the shifts in bargaining positions, as measured by $\left|\pi_{F}-\pi_{A}\right|$, only influence how the surplus generated by the alliance is divided between $F$ and $A$. The condition for the efficiency of knowledge sharing, $V>I$, does not depend on the relative magnitudes of $\pi_{F}$ and $\pi_{A}$. Because $V-I \geq\left|\pi_{F}-\pi_{A}\right|$ is stronger than $V>I$, as typical in property-rights models, the equilibrium can exhibit underinvestment.

We summarize this discussion as follows.

Proposition 1. Knowledge sharing is efficient when $V \geq I$. However, it is privately profitable for both firms only when

$$
V-I \geq\left|\pi_{F}-\pi_{A}\right|
$$

Proposition 1 captures the idea that some value-creating investments may not be undertaken when knowledge sharing creates large shifts in bargaining positions. Value creation is important but asymmetries in the evolution of outside options create a wedge between equilibrium and socially efficient outcomes. Preserving the balance of power within the alliance (a low $\pi_{F}-\pi_{A}$ in absolute value) helps reduce the risk of underinvestment.

By emphasizing underinvestment in knowledge sharing rather than the failure of an alliance to be formed, we implicitly assume that, despite underinvestment, the partners may still remain together, as was the case in the Nypro-Vistakon example discussed above. The SEMATECH alliance is another case in point. As Grindley et al. (1994: 730) write, SEMATECH was

[o]riginally intended to provide a research facility for member firms to collaborate on projects to improve their semiconductor manufacturing process technology. [However,...] Process technology expertise is central to the competitive advantage of individual semiconductor manufacturers, and member firms were reluctant to share such sensitive information. The sophistication of the manufacturing technology of SEMATECH member firms also differed considerably, raising the danger that some firms could "free ride" on the contributions of technology leaders.

\footnotetext{
${ }^{10}$ This is not sufficient for knowledge sharing because if $F$ believes that $A$ will not invest, then, $F$ will not invest even if $V-I \geq\left|\pi_{F}-\pi_{A}\right|$. Here we ignore this coordination problem.
} 
In response to these controversies, SEMATECH altered its research agenda [...] The new research agenda has shifted the consortium's focus from the development of a complete state-ofthe-art production process in its Austin facility to knowledge diffusion and technology transfer.

SEMATECH provides another example where appropriability hazards and competitive tensions among member firms prevented participants from fully sharing their knowledge. However, appropriability hazards did not lead to the termination of the alliance. Instead, the goal of the alliance was altered, to focus on areas where competitive tensions were less severe.

In addition to noncontractible investment, several other features of the model are also well-suited for the analysis of knowledge sharing. In our model, partners' investments are highly complementary ( $V$ is only created if both partners invest). Our results remain valid for arbitrarily small investment costs. ${ }^{11} \mathrm{~A}$ firm's investment may affect not only its own outside option, but also the outside option of its partner. It is difficult to think of many investments not involving knowledge sharing where all these assumptions are verified. Also, the next section will consider investments in absorptive capacity. There, we will show that a 'strong' partner may invest resources to restrict its own absorptive capacity, thus lowering the value of its outside option. In the case of more traditional investments in physical or human capital, we would instead expect investment to improve one's own outside options.

\subsection{Uncertainty}

This subsection explores how uncertainty affects firms' incentives to share knowledge. We consider two scenarios: symmetric resolution of uncertainty about synergies and asymmetric resolution of uncertainty about outside options. We find that, contrary to conventional wisdom, uncertainty often promotes knowledge sharing in our setting.

Symmetric resolution of uncertainty about synergies. We begin with the case where there is initially uncertainty about the value of the synergies $V$. In period 1 (the knowledge sharing stage), $F$ and $A$ only know that $V$ is distributed according to cumulative distribution function $G$ over support $[\underline{V}, \bar{V}]$. However, in period 2 (after knowledge sharing but before implementation), both firms learn the

\footnotetext{
${ }^{11}$ We assumed $I>0$ to rule out some knife-edge equilibria and simplify the exposition. The analysis would remain essentially unchanged if we had assumed $I \geq 0$ instead.
} 
realization of $V$. Thus, there is symmetric information in period 3 (the negotiating stage). We assume $\bar{V}>\pi_{F}+\pi_{A}>\underline{V}$, so that, if synergies $V$ are low, it is efficient to terminate the alliance after knowledge sharing. Firms are risk neutral. All other features of the model remain the same.

In this setting, it is optimal for $F$ to share knowledge (conditional on $A$ sharing knowledge) if

$$
\pi_{F}+\frac{1}{2} \int_{\pi_{F}+\pi_{A}}^{\bar{V}}\left(V-\pi_{F}-\pi_{A}\right) d G \geq \frac{1}{2} I .
$$

Similarly, it is optimal for $A$ to share knowledge (conditional on $F$ sharing knowledge) if

$$
\pi_{A}+\frac{1}{2} \int_{\pi_{F}+\pi_{A}}^{\bar{V}}\left(V-\pi_{F}-\pi_{A}\right) d G \geq \frac{1}{2} I .
$$

Intuitively, if firms share their knowledge, they appropriate their outside options $\left(\pi_{F}\right.$ or $\left.\pi_{A}\right)$ plus half of the surplus, which accrues only when synergies are sufficiently high $\left(V \geq \pi_{F}+\pi_{A}\right)$. By contrast, the condition for efficient knowledge sharing is

$$
\pi_{F}+\pi_{A}+\int_{\pi_{F}+\pi_{A}}^{\bar{V}}\left(V-\pi_{F}-\pi_{A}\right) d G \geq I .
$$

Proposition 2 characterizes the equilibrium under synergy uncertainty and shows how greater uncertainty (modelled as a mean preserving spread of the original distribution $G$ ) affects knowledge sharing.

\section{Proposition 2.}

(i). The equilibrium can exhibit underinvestment in knowledge sharing.

(ii). Early termination of an alliance (before implementation) occurs with positive probability, but is always efficient.

(iii). An increase in uncertainty about synergies makes investment in knowledge sharing more likely.

As in the model without uncertainty, the non-cooperative equilibrium can exhibit underinvestment in knowledge sharing. However, unlike the baseline model, now an alliance can be terminated early-after knowledge sharing but before implementation - if synergies turn out to be low. Proposition 2 also shows that the incentives for knowledge sharing are greater when there is more uncertainty about the value of synergies. Intuitively, a mean preserving spread of the distribution of $V$ increases the likelihood of extreme 
(very low and very high) realizations of $V$. If $V$ is very low, after knowledge sharing the partners can still obtain $\pi_{F}$ and $\pi_{A}$. The downside is therefore limited. On the other hand, if $V$ is very high, the partners can share this large value. This upside of knowledge sharing increases as more extreme realizations of $V$ become possible. In short, there is an option value associated with knowledge sharing, and the value of that option increases with the level of uncertainty over synergies.

Asymmetric resolution of uncertainty about outside options. Next, we consider a scenario where there is initially uncertainty about one of the partners' (ex post) outside options, namely $\pi_{A}$. In period 1 (the knowledge sharing stage), $F$ and $A$ only know that $\pi_{A}$ is distributed according to some distribution function. In period 2 (after knowledge sharing but before implementation), $A$ learns the realization of $\pi_{A}$, but $F$ learns nothing. Thus, in period 3 (the negotiating stage), there is one-sided asymmetric information (where $A$ has an informational advantage). For tractability, we assume that $\pi_{A}$ is distributed uniformly on $\left[0, V-\pi_{F}\right]$. Note that, because $V \geq \pi_{F}+\pi_{A}$ for all realizations of $\pi_{A}$, premature termination of the alliance is never efficient. Firms are risk neutral.

The project is implemented if the firms agree on a division of $V$. Bargaining occurs as follows. With probability $1 / 2, F$ makes a take-it-or-leave-it offer to $A$, and with probability $1 / 2, A$ makes a take-it-orleave-it offer to $F$. This procedure, if $\pi_{A}$ was known to both partners, would produce exactly the same outcome (in expectation) as the Nash bargaining solution in Section 2. All other features of the model remain the same.

We compare this one-sided asymmetric information scenario to a benchmark scenario where $\pi_{A}$ is

nonstochastic and given by $\frac{V-\pi_{F}}{2}$ (the expected value of $\pi_{A}$ when $\pi_{A}$ is distributed uniformly on $[0, V-$ $\left.\pi_{F}\right]$ ). Welfare is defined as the sum of the firms' expected payoffs in period 1 (before the resolution of uncertainty). We can show the following.

\section{Proposition 3.}

(i). In the one-sided asymmetric information scenario, premature termination of the alliance occurs with positive probability and is inefficient. In the benchmark scenario, premature termination of the alliance never occurs. 
(ii). Despite this inefficiency, investments in knowledge sharing and welfare can be higher in the one-sided asymmetric information scenario than in the benchmark scenario. ${ }^{12}$

Proposition 3 shows that, although asymmetric information always creates an inefficiency relative to the first best, compared to a benchmark scenario with complete information, asymmetric information can improve welfare. The intuition is as follows. When making an offer $x$ at the negotiating stage, the uninformed player (firm $F$ ) trades-off a smaller gain $V-x$ when the offer is accepted for a greater probability $\operatorname{Pr}\left(\pi_{A} \leq x\right)$ that the offer is accepted. In the optimum, therefore, $F$ 's makes an offer which is rejected with positive probability. This is inefficient and welfare is reduced.

However, the incentives to share knowledge can be higher in the one-sided asymmetric information scenario than in the benchmark scenario. The reason is that asymmetric information improves the bargaining position of the informed party $(A)$. Knowledge sharing may not be possible with symmetric information (because $\pi_{F}$ is much larger than $\pi_{A}$ ), but asymmetric information can improve $A$ 's bargaining position so much that knowledge sharing is possible under one-sided asymmetric information. Thus, asymmetric information can help balance an initially unbalanced relationship.

\section{Commitments to encourage knowledge sharing}

So far we have shown that appropriability hazards can lead to underinvestment in knowledge sharing. Next, we consider commitments that prospective partners can make to encourage knowledge sharing when appropriability hazards are severe. These strategies include: (i) restricting one's own absorptive capacity, (ii) alliance portfolio design, and (iii) contractual solutions. Throughout, we will assume with no essential loss of generality that $F$ is the "strong" partner, in the sense that $\pi_{F}>\pi_{A}$. Thus, the binding knowledge sharing constraint will generally be that of the "weak" partner $A .{ }^{13}$

\subsection{Restricting one's own absorptive capacity}

An influential literature in strategy stresses that attempts to appropriate the returns from collaboration may generate learning races, where partners try to absorb their partners' knowledge while protecting their

\footnotetext{
${ }^{12}$ In the proof of Proposition 3 in Appendix A, we provide a precise characterization of the set of parameter values for which welfare is higher in the one-sided asymmetric information scenario than in the benchmark scenario.

${ }^{13}$ In the alliance portfolio case, identifying whose knowledge sharing constraint is binding is less straightforward.
} 
own (e.g., Hamel, 1991; Khanna et al., 1998). Our model suggests that strengthening one own's bargaining position beyond a point may be counterproductive because it may discourage knowledge sharing.

In this section we develop a simple extension of the model where firms invest in their ability to absorb external knowledge, which in turn improves their bargaining position vis-à-vis their partner. We show that, when the need of encouraging knowledge sharing is taken into account, firms do not always want to maximize their receptivity to their partners' knowledge. Instead, they may sometimes intentionally restrict their own learning capability to encourage knowledge sharing. Thus, the model can potentially explain why in reality firms seldom appear to exhibit a racing intent (Mowery et al., 1996; Hennart et al., 1999; Inkpen, 2000) and their behavior is instead best described as cooperative (Inkpen, 2005).

We assume that, in period 0 (prior to the knowledge sharing stage), firms invest in their absorptive capacity. These investments are irreversible, observable and affect firms' outside options in case of premature termination of the alliance. ${ }^{14}$ Specifically, we assume that, if firm $i=F, A$ chooses a low absorptive capacity in period 0 (at $\operatorname{cost} c_{i}^{L}$ ), then its ex post outside option in period 2 (following knowledge sharing and premature termination of the alliance) is $\pi_{i}^{L}$. Conversely, if firm $i$ chooses a high absorptive capacity (at $\operatorname{cost} c_{i}^{H}$ ), then in period 2 its ex post outside option is $\pi_{i}^{H}$, where $\pi_{i}^{H}>\pi_{i}^{L}$ and $V \geq \pi_{F}^{H}+\pi_{A}^{H}$, so that premature termination of the alliance is not efficient. ${ }^{15}$

The learning race literature suggests that $F$ should select $\pi_{F}^{H}$ and $A$ should select $\pi_{A}^{H}$. To bias the results in this direction, we assume that investments in absorptive capacity are equally costly (i.e., $c_{F}^{H}=c_{F}^{L}$ and $\left.c_{A}^{H}=c_{A}^{L}\right)$. Thus, deviations from the outcome $\left(\pi_{F}^{H}, \pi_{A}^{H}\right)$ must emerge not from cost considerations, but for purely strategic reasons. We will interpret the choice of the strong partner $F$ to restrict its own absorptive capacity (i.e., to choose $\pi_{F}^{L}$ instead of $\pi_{F}^{H}$ ) as a commitment to encourage knowledge sharing. Finally, to reduce the number of cases to consider, we assume that $\pi_{F}^{L} \geq \pi_{A}^{H}$. This implies that the focal firm $F$ is always the "faster learner" (or stronger partner), while $A$ is always the "slower learner" (or

\footnotetext{
${ }^{14}$ Irreversibility and observability are key features of credible commitments (Schelling, 1960; Morgan and Várdy, 2013). For a commitment to an action to be credible, the commitment must be irreversible, or at least reneging must be sufficiently costly. In our model, irreversibility is captured by a sequential choice of actions. The assumption that a commitment to an action is observable may not always be warranted in practice. Below, we illustrate how a commitment to protect a partner's confidential information can be made visible, with reference to Intel's well-publicized distinction between "Job 1" and "Job $2 "$.

${ }^{15}$ Allowing larger investments in absorptive capacity to also increase the joint value $V$ does not pose any difficulties but neither does it provide any insights.
} 
weaker partner). All other features of the model in Section 2 remain the same.

Proposition 4 below shows that the learning race intuition is in general incorrect. Partners do sometimes engage in learning races and maximize their absorptive capacity (case (iii) below). However, in some circumstances they purposefully limit their absorptive capacity and increase their partner's payoff (case (ii)).

Proposition 4. Suppose knowledge sharing is efficient $(V \geq I)$, firm $F$ is always the faster learner $\left(\pi_{F}^{L} \geq \pi_{A}^{H}\right)$, and investments in absorptive capacity are equally costly $\left(c_{F}^{H}=c_{F}^{L}\right.$ and $\left.c_{A}^{H}=c_{A}^{L}\right)$. In equilibrium:

(i) If $V-I<\pi_{F}^{L}-\pi_{A}^{H}$, the firms do not invest in knowledge sharing. The choices of absorptive capacity are inconsequential.

(ii) If $V-I \in\left[\pi_{F}^{L}-\pi_{A}^{H}, \pi_{F}^{H}-\pi_{A}^{H}\right)$, the firms invest in knowledge sharing. Firm $F$ selects $\pi_{F}^{L}$ and firm A selects $\pi_{A}^{H}$.

(iii) If $V-I \geq \pi_{F}^{H}-\pi_{A}^{H}$, the firms invest in knowledge sharing. Firm $F$ selects $\pi_{F}^{H}$ and firm A selects $\pi_{A}^{H}$.

Proposition 4 shows that, when firms are very asymmetric in terms of their absorptive capacities (case (i)), knowledge sharing does not occur. Asymmetries lead to a breakdown of cooperation, and the resulting outcome is inefficient. If instead firms are relatively similar in terms of their absorptive capacities (case (iii)), a learning race takes place. Both firms maximally invest in absorptive capacity, but this still leads to a fairly symmetric outcome. Thus, they still find it privately profitable to invest in knowledge sharing.

The most interesting case arises when absorptive capacities are asymmetric but not excessively so (case (ii)). A strategy of maximizing absorptive capacity becomes self-defeating for the stronger partner $F$. By maximizing its absorptive capacity, firm $F$ discourages firm $A$ from sharing its knowledge. $F$ is better off by limiting its absorptive capacity to $\pi_{F}^{L}$, thus sharing more surplus with $A$.

There are many examples of firms that appear to deliberately reduce their own absorptive capacity to facilitate cooperation with their partners. Cisco, for instance, is a firm that has successfully managed 
a large number of alliances in a variety of sectors, geographies and technological areas. Cisco recognizes that conflicts can arise when partners are exposed to each other's knowledge. Steve Steinhilber, Vice President of strategic alliances at Cisco, notes that:

One of the most contentious issues in negotiating the confidentiality terms of an alliance agreement is the treatment of residuals - that is, general knowledge, know-how, and the skills that each partner's employees will gain by being exposed to the other party's confidential information (2008: 101). [...] you face considerable risk [...]. You could open your doors to a company that could hurt you in your own market over time, gain competitive advantages, or acquire unique knowledge or skills that it could not have obtained otherwise (2008: 114).

Steinhilber recommends that partners establish ground rules to manage information security and intellectual property rights. These rules should be designed not simply to protect one own's resources, but also to ensure that all the partners are treated fairly and nobody's knowledge is mishandled. In particular, Steinhilber suggests that firewalls may sometimes be created to prevent Cisco from learning too much from its partners. Specifically, he recommends:

Setting clear parameters in your agreements that identify the information to be shared and the permitted use of such information. In certain instances, it may be necessary to restrict information to some employees and to set up firewalls to prevent tainting other groups within the company that are developing similar technology independently. [...] Setting up training and procedures to protect your partner's confidential information and watching for actions by your partner that may signal an improper use of your own information (2008: 119; emphasis added).

In the context of our model, we can interpret Cisco's internal "Chinese walls" as a commitment to reduce its own absorptive capacity. If the relationship between Cisco and one of its partners were to break down, Cisco would arguably see no impediment to removing these barriers and using any information that it may have gleaned during the collaboration. However, this information would only be transmitted with delay, after the alliance has been terminated and the communication barriers have been removed. These delays would imply lower rival benefits $\pi_{F}$ to Cisco and higher rival benefits $\pi_{A}$ to its partner (because competition between Cisco and the partner would be delayed). Both effects would encourage Cisco's partners to invest in knowledge sharing.

Toyota and Intel provide further illustrations of how setting up internal Chinese walls can facilitate collaboration. Toyota benefits greatly from the development and diffusion of production knowledge within 
its supplier network. To encourage partners to share their knowledge, Toyota took the conscious decision to separate its operations management consulting division from its purchasing division, "so that suppliers can work with the consultants without fearing that purchasing will ask for a price decrease after the consultation" (Dyer and Nobeoka, 2000: 358-359). As Hajime Ohba, the head of Toyota Supplier Support Center, notes: "Our job is to help suppliers improve, not to worry about who gets the additional profits" (quoted in Dyer and Nobeoka, 2000: 359). Because suppliers appropriate in the short run a large fraction of the benefits from collaboration, this arrangement gives them strong incentives to participate in knowledge sharing activities.

Intel also faces significant tensions when collaborating with partners (Gawer and Cusumano, 2002). On the one hand, Intel wants to expand demand for its microprocessors ("Job 1"), which requires encouraging the entry of complementary products such as new graphics cards and chip sets. On the other hand, Intel also wants to grow profitable businesses in complementary markets ("Job 2"). Intel's dilemma is how to encourage "complementors" to enter, while ex post it may have an incentive to compete with them. Gawer and Cusumano argue that one method is to create separate groups or divisions pursuing Job 1 or 2. For example, the Intel Architecture Lab (IAL) was explicitly structured as a cost center and rewarded for its success in promoting the health of the whole ecosystem (Job 1). As Andy Grove notes: "IAL has no profit-and-loss responsibility, and no products. [...] And IAL has achieved an extra measure of credibility. It comes, first, from the fact that they are very good, and second, that they are not in a business" (quoted in Gawer and Cusumano, 2002: 128; emphasis in original).

IAL head Craig Kinnie (also quoted in Gawer and Cusumano, 2002: 128) similarly notes the importance of IAL being perceived as fair and impartial. Consistent with the literature on credible commitments and our model, he also emphasizes that the separation of roles between IAL and other Intel units must be externally visible:

To deserve the trust, a separation of roles inside the organization is an absolute necessity. And it has to be observable from the outside. There is a tension between the two perspectives: the Lab perspective and the product groups' perspective. [...] It is also important to keep that polarity for the sake of enrolling others on the outside. If the labs were buried inside of the product groups, the perceived neutrality and trustworthiness of the labs would go down. 
Taken together, these examples suggest that commitments to protect a partner's confidential information can help encourage knowledge sharing in alliances. Interestingly, and in line with our model, in all the above examples it was the leading firm (Cisco, Intel, Toyota) that reduced its own absorptive capacity. Clearly, incumbents do not always behave like "sharks", but sometimes adopt apparently altruistic behaviors, motivated by the need to engender trust and encourage knowledge sharing. ${ }^{16}$

\section{Alliance portfolio design}

In this section we study how alliance portfolios can be designed to facilitate knowledge sharing. We assume that, in period 0 , the focal firm $F$ chooses (i) whether to be involved in one or more dyadic alliances and, if it is involved in more than one alliance, (ii) the degree of similarity among its alliance partners. The key contribution of this section is to distinguish between two types of substitutability and show that there is a type of substitutability that facilitates, not hinder, knowledge sharing. We also show that, regardless of which type of substitutability is more important, $F$ typically benefits from choosing partners that are neither too similar nor too dissimilar from each other. A key message of this section is that, because there is a 'good' type of substitutability, alliance portfolios can facilitate knowledge sharing. Knowledge sharing may not be feasible in a single alliance, but may be feasible in a portfolio.

\subsection{Partner substitutability and knowledge sharing}

A recent literature focuses on alliance portfolios and interdependencies among partners. At the risk of simplifying a complex subject, this literature suggests that overlaps among alliance partners reduce value: they reduce the potential for synergies and increase conflict among partners. The result, according to this logic, is lower stability of alliances and lower value to the focal firm (e.g., Vasudeva and Anand, 2011; Wassmer and Dussauge, 2011). ${ }^{17}$

\footnotetext{
${ }^{16}$ The model can also be extended to examine the issue of the opacity of a firm's operations. The learning race literature argues that firms should minimize the transparency of their own operations, thus reducing their partners' absorptive capacity. In terms of our model, $F$, instead of increasing its own absorptive capacity (leading to a higher $\pi_{F}$ ), could reduce the transparency of its own operations (leading to a lower $\pi_{A}$ ). Arguments analogous to the ones in Proposition 4 show that, in some cases, a leading firm $F$ may find it beneficial to increase the transparency of its own operations. An example would be Toyota opening its operations to General Motors, to teach its partner (and competitor) valuable lean manufacturing practices (Inkpen, 2005).

${ }^{17}$ On the other hand, as Lavie (2007) notes, greater overlap among alliance partners increases the relative bargaining power of the focal firm. Cui (2013) argues that similarity or redundancy of resources among alliance partners may benefit the focal firm by securing access to resources in uncertain environments.
} 
We revisit these ideas through the lens of our model. We consider a setting where a focal firm $F$ collaborates with two partners, $A$ and $B$. Thus, there are two dyadic alliances, one between $F$ and $A$, and one between $F$ and $B$. We say that $A$ and $B$ are substitutes if they allow $F$ to access similar pools of knowledge. We distinguish between two types of substitutability: substitutability in implementation and substitutability in rival benefits.

Substitutability in implementation refers to situations where the contribution of a former partner to the implementation of a project can partly be replaced by the contribution of the staying partner. For instance, suppose $F$ and $A$ share knowledge to develop new artificial intelligence (AI) algorithms. If this alliance is prematurely terminated (after knowledge sharing but before implementation), $F$ may be able to develop its own algorithms (a "rival" project). In implementing this rival project, F's other (staying) partner may help. Specifically, if the alliance between $B$ and $F$ is not prematurely terminated, the value of the rival project will increase from $\pi_{F}$ to $\pi_{F}+s^{\operatorname{Imp}}$. Here, $s^{\operatorname{Imp}} \geq 0$ measures the value of $B$ 's contribution to the implementation of the rival project. ${ }^{18}$

By contrast, substitutability in rival benefits refers to situations where the knowledge gained by former partners is partly overlapping, so that the rival benefits from prematurely terminating both alliances are lower. For example, suppose $F$ acquires AI competencies from both $A$ and $B$ and there are two rival projects where $F$ can redeploy these capabilities: algorithms for image classification and algorithms for speech recognition. Suppose further that algorithms for image classification are more valuable to $F$ than algorithms for speech recognition. If only one alliance is prematurely terminated (say the one with $A$ ), then $F$ could redeploy the engineers working with $A$ to work on image classification, thus yielding rival benefits $\pi_{F}$. However, if both alliances are prematurely terminated, both the engineers working with $A$ and the engineers working with $B$ could be redeployed. One group would work on image classification, yielding rival benefits $\pi_{F}$, while the other group would work on speech recognition, yielding rival benefits $\pi_{F}-s^{R B}$, so that F's total payoff would be $2 \pi_{F}-s^{R B}$. Here $s^{R B} \geq 0$ measures substitutability in rival benefits. This notion captures the idea that, if $A$ and $B$ 's knowledge bases are similar, the marginal returns to prematurely terminating multiple alliances are likely to be decreasing.

\footnotetext{
${ }^{18}$ By contrast, if the alliance between $F$ and $B$ is prematurely terminated, then $B$ will not be willing to help $F$ with the rival project.
} 
We incorporate these two notions of substitutability in a simple extension of the model studied in Section 2. To reduce notation, we assume that F's alliances are completely symmetric in terms of payoffs. Thus, for instance, $F$ obtains the same baseline outside option (or rival benefit) $\pi_{F}$, regardless of whether the alliance with $A$ or $B$ is prematurely terminated. If neither pair shares knowledge, all firms obtain the same payoffs, normalized to zero. $A$ and $B$ 's outside options following premature termination are also set for simplicity equal to zero: $\pi_{A}=\pi_{B}=0$.

We begin with the case where $F$ and $A$ share knowledge, but $F$ and $B$ do not. Then, it is as if $B$ did not exist and the analysis follows the same steps as in Section 2. Knowledge sharing is efficient if $V \geq I$; however, it is privately profitable for both $F$ and $A$ only if $V-I \geq \pi_{F}$. Thus, in equilibrium there can be underinvestment in knowledge sharing.

Next, consider the case where knowledge sharing occurs in both alliances. Let $v(S)$ be the value created by coalition $S \in\{F, A, B, F A, F B, A B, F A B\}$ when (i) the firms in $S$ implement their projects together and (ii) the alliances between the firms in $S$ and the firms not in $S$ are terminated prematurely. Thus, $v(F A B)$ is the value created by coalition $F A B$ when both $F$ and $A$ and $F$ and $B$ implement their projects together. $v(F A)$ is the value created by coalition $F A$ when $F$ and $A$ implement their project together but the alliance between $F$ and $B$ is prematurely terminated. $v(A)$ is the value created by $A$ when the alliance between $F$ and $A$ is prematurely terminated. ${ }^{19}$ All values $v$ are gross of knowledge sharing costs.

We assume $v(F A B)=2 V+b . V$ is the 'baseline' value created by $F$ and $A$ (or $F$ and $B$ ) working together. The synergistic benefit $b \geq 0$ captures complementarities between $A$ and $B$ in implementation. By combining $A$ and $B$ 's capabilities during the implementation stage, the coalition $F A B$ creates $b$ more value than if $A$ and $B$ were involved in two completely unrelated alliances. When the alliance between $F$ and $B$ is terminated prematurely, the coalition $F A$ obtains $v(F A)=V+\pi_{F}+s^{I m p}$, where $V$ is the value created by $F$ and $A$ implementing their project together and $\pi_{F}+s^{\operatorname{Imp}}$ is the value created by $F$ and $A$ working on the rival project originating from the terminated alliance with $B$. We assume $s^{\operatorname{Imp}} \in\left[0, V-\pi_{F}\right]$, which implies that prematurely terminating an alliance is not efficient.

\footnotetext{
${ }^{19}$ Whether or not the alliance between $F$ and $B$ is prematurely terminated is irrelevant for $\operatorname{determining} v(A)$. In both cases, we assume $v(A)=0$.
} 
If both alliances are terminated prematurely, the values created by coalitions $F, A$ and $B$ are, respectively $v(F)=2 \pi_{F}-s^{R B}, v(A)=0$ and $v(B)=0$. Non-focal partners always get a payoff of 0 if they do not implement their projects with $F$. The focal partner $F$, by contrast, can work on two rival projects, earning $2 \pi_{F}-s^{R B}$, where $s^{R B}$ measures substitutability in rival benefits. We assume $s^{R B} \in\left[0, \pi_{F}\right] .^{20}$

Table 1 summarizes the values created by all the possible non-empty coalitions following knowledge sharing. If the alliances between $F$ and $A$ and $F$ and $B$ were completely unrelated, we would have $b=s^{I m p}=s^{R B}=0$.

TABLE 1: Coalitional values after knowledge sharing

\begin{tabular}{|l|c|}
\hline $\begin{array}{l}\text { Neither collaboration is } \\
\text { terminated prematurely }\end{array}$ & $v(F A B)=2 V+b$ \\
\hline $\begin{array}{l}\text { One and only one } \\
\text { collaboration is terminated } \\
\text { prematurely }\end{array}$ & $v(F A)=v(F B)=V+\pi_{F}+s^{\text {Imp }}$ \\
\hline $\begin{array}{l}\text { Both collaborations are } \\
\text { terminated prematurely }\end{array}$ & $v(F)=2 \pi_{F}-s^{R B}$ \\
& $v(A)=v(B)=0$ \\
\hline
\end{tabular}

Following Hart and Moore (1990), we use the Shapley value to assign payoffs to individual firms. If knowledge sharing occurs, then the "grand coalition" FAB will emerge because it creates the greatest total value. ${ }^{21}$ The Shapley value assigns each firm its expected marginal contribution assuming that the order in which they joint the grand coalition is random. Formally, for $i=F, A, B$ and any subset of firms $S \subseteq N=\{F, A, B\}$, the value assigned to firm $i$ is:

$$
\phi_{i}=\sum_{S \subseteq N \backslash\{i\}} \frac{|S| !(|N|-|S|-1) !}{|N| !}(v(S \cup\{i\})-v(S))
$$

where $|S|$ denotes the number of firms in $S$ and, for any positive integer $r, r !=1 \times 2 \times \ldots \times r$, and $0 !=1$.

\footnotetext{
${ }^{20} s^{R B}=\pi_{F}$ would capture a situation where either $A$ or $B$ 's knowledge is completely redundant in creating rival benefits. $s^{R B}<0$ represents complementarities in rival benefits. For instance, if a large mass of AI scientists was necessary to create substantial rival benefits, the partners are complements in rival benefits.

${ }^{21}$ Indeed, $s^{I m p} \in\left[0, V-\pi_{F}\right]$ implies that coalitional values $v$ satisfy superadditivity: $v(S \cup T) \geq v(S)+v(T)$ for any two disjoint set of firms $S$ and $T$.
} 
The Shapley value yields the expressions for the firms' (gross) payoffs: ${ }^{22}$

$$
\begin{gathered}
\phi_{F}=V+\pi_{F}+\frac{1}{3} b+\frac{1}{3}\left(s^{I m p}-s^{R B}\right) \\
\phi_{A}=\phi_{B}=\frac{1}{2}\left(V-\pi_{F}\right)+\frac{1}{3} b-\frac{1}{6}\left(s^{\operatorname{Imp}}-s^{R B}\right) .
\end{gathered}
$$

As the single alliance case, the fact that $F$ can use the knowledge learnt from its partners on rival projects shifts the balance of power in its favor $-F$ gets an additional $\frac{1}{2} \pi_{F}$ from each partner, and $A$ and $B$ lose the same amount. The synergistic value $b$ is created only if all the firms work together; hence $b$ is split equally among them. Substitutability in implementation has both costs and benefits for $A$ and $B$. On the one hand, $A$ can be replaced by $B$, which lowers $A$ 's bargaining power vis-à-vis $F$. On the other hand, $A$ may replace $B$. In this case, $A$ will share the benefits of substitutability in implementation with $F$. The cost of lower bargaining power for $A$ (and similarly for $B$ ) is $\frac{1}{3} s^{\operatorname{Imp}}$, while the benefit of replacing $B$ is just $\frac{1}{6} s^{I m p}$. The benefit is half the cost because the gains from replacing $B$ does not just accrue to $A$, but must be split between $A$ and $F$. Thus, $A$ and $B$ on average lose as a result of implementation substitutability, and $F$ gains. Finally, substitutability in rival benefits $s^{R B}$ lowers the outside option of the focal firm $F$ in case both alliances are terminated and therefore weakens $F$ 's bargaining position vis-à-vis $A$ and $B$. Thus, $s^{R B}$ appears with a negative sign in equation (9), and with a positive sign in equation (10).

Define $\Pi_{F}=\phi_{F}-I, \Pi_{A}=\phi_{A}-\frac{1}{2} I$ and $\Pi_{B}=\phi_{B}-\frac{1}{2} I$. Knowledge sharing in both alliances is privately profitable for all partners if $\Pi_{i} \geq 0$ for all $i=F, A, B$. Knowledge sharing in both alliances is efficient if $2 V+b \geq 2 I$. To facilitate the comparison with the single alliance case, we assume that the knowledge sharing condition for the focal firm holds i.e., $\Pi_{F} \geq 0$, but those of the "weak" partners may not hold. We have the following.

Proposition 5. Suppose $V \geq I$. In alliance portfolios:

\footnotetext{
${ }^{22}$ To compute $\phi_{F}$, one can proceed as follows. There are six possible ways in which firms $F, A$ and $B$ can be ordered: $F A B, F B A, A F B, B F A, A B F$ and $B A F$. The marginal contribution of $F$ when $F$ is the first firm to join the grand coalition (orderings $F A B$ and $F B A$ ) is $v(F)-v(\varnothing)=2 \pi_{F}-s^{R B}$. The marginal contribution of $F$ when $F$ is the second firm to join the grand coalition (orderings $A F B$ and $B F A$ ) is $v(A F)-v(A)=v(B F)-v(B)=V+\pi_{F}+s^{\text {Imp }}$. The marginal contribution of $F$ when $F$ is the third firm to join the grand coalition (orderings $A B F$ and $B A F)$ is $v(A B F)-v(A B)=$ $v(B A F)-v(B A)=2 V+b$. Because all orderings are equiprobable, we obtain equation (9). $\phi_{A}$ and $\phi_{B}$ are computed similarly.
} 
(i). Substitutability in rival benefits facilitates knowledge sharing, while substitutability in implementation hinders it. Synergies in implementation also facilitate knowledge sharing.

(ii). Synergies in implementation have a larger effect in facilitating knowledge sharing than substitutability in implementation has in hindering it. More precisely, suppose $b=k_{1}+\lambda$ and $s^{\operatorname{Imp}}=k_{2}+\lambda$. Then knowledge sharing becomes more likely in alliance portfolios as $\lambda$ grows.

These results follow from the knowledge sharing constraints of the "weak" partners:

$$
\Pi_{A}, \Pi_{B} \geq 0 \Leftrightarrow V-I-\pi_{F}+\frac{2}{3} b-\frac{1}{3}\left(s^{I m p}-s^{R B}\right) \geq 0 .
$$

The analysis suggests two reasons why substitutability may not be as bad at discouraging knowledge sharing as generally thought. First, we identify a type of substitutability, substitutability in rival benefits $s^{R B}$, which facilitates rather than hinders knowledge sharing. Second, we show that synergies in implementation $b$ have a larger effect in facilitating knowledge sharing than substitutability in implementation $s^{\operatorname{Imp}}$ has in hindering it. The reason, as mentioned above, is that substitutability in implementation has some beneficial effects for non-focal partners. A non-focal partner may lose a lot when it is replaced, but it may also gain a little when it is instrumental in replacing another non-focal partner.

An implication of our analysis is that knowledge sharing in a portfolio can be feasible, while knowledge sharing in a single alliance may not be.

Proposition 6. Suppose $V \geq I$. If $V-I \in\left[\pi_{F}-\frac{2}{3} b+\frac{1}{3}\left(s^{I m p}-s^{R B}\right), \pi_{F}\right)$, then knowledge sharing in a portfolio is feasible, while knowledge sharing in a single alliance is not.

Proposition 6 suggests that one way to encourage knowledge sharing when appropriability hazards are present is to create alliance portfolios with desirable characteristics. The strategy of adding a third partner (i.e., a second dyadic alliance) is beneficial not only when there are synergies in implementation between non-focal partners, but also when substitutability in rival benefits is significant.

\subsection{Similarity between alliance partners}

Besides selecting the "right" number of partners, a focal firm must also select partners with the "right" characteristics. Here we examine the following question: Should the focal firm $F$ choose non-focal partners 
that are similar to each other (i.e., with a large degree of substitutability), or partners that are different from each other (with a low degree of substitutability)?

To answer this question, let $s^{\operatorname{Imp}}=\alpha \Psi$ and $s^{R B}=(1-\alpha) \Psi$. The parameter $\Psi \geq 0$ measures the degree of similarity between $A$ and $B$. A high degree of similarity between $A$ and $B$ increases both substitutability in implementation and substitutability in rival benefits. $\alpha \in[0,1]$ is a parameter capturing to what extent substitutability in implementation is more important than substitutability in rival benefit. If $\alpha=1$, then only substitutability in implementation matters. If $\alpha=0$, then only substitutability in rival benefit is important. By varying $\alpha$, we can examine how our results depend on the type of substitutability.

Proposition 7 below shows that, regardless of which type of substitutability is more important, $F$ should often choose partners that are neither too similar or too dissimilar from each other.

Proposition 7. Suppose $s^{\operatorname{Imp}}=\alpha \Psi$ and $s^{R B}=(1-\alpha) \Psi$, where $\Psi \geq 0$ and $\alpha \in[0,1]$.

(i). If $\alpha<\frac{1}{2}$ and $V-I-\pi_{F}+\frac{2}{3} b \leq 0$, then $F$ 's equilibrium payoff first rises then declines with $\Psi$. The optimum level of similarity from $F^{\prime}$ 's viewpoint is $\Psi^{*}=\frac{3\left(V-I-\pi_{F}\right)+2 b}{2 \alpha-1}$.

(ii). If $\alpha<\frac{1}{2}$ and $V-I-\pi_{F}+\frac{2}{3} b>0$, then $F$ 's equilibrium payoff monotonically declines with $\Psi$. The optimum level of similarity from F's viewpoint is zero.

(iii). If $\alpha>\frac{1}{2}$ and $V-I-\pi_{F}+\frac{2}{3} b \leq 0$, then $F$ 's equilibrium payoff is independent of $\Psi$ and always equal to 0 .

(iv). If $\alpha>\frac{1}{2}$ and $V-I-\pi_{F}+\frac{2}{3} b>0$, then $F^{\prime}$ 's equilibrium payoff first rises then declines with $\Psi$. The optimum level of similarity from $F$ 's viewpoint is $\Psi^{*}=\frac{3\left(V-I-\pi_{F}\right)+2 b}{2 \alpha-1} .{ }^{23}$

Proposition 7 suggests that the relationship between the value that $F$ can appropriate and the degree of similarity of its alliance partners is typically non-monotonic. The reason is that there are in general two conflicting effects at play: (i) on the focal firm's payoff conditional on knowledge sharing and (ii) on the weak partners' incentives to share knowledge.

\footnotetext{
${ }^{23}$ If $\alpha=\frac{1}{2}$, then $F$ 's equilibrium payoff is independent of $\Psi$ and equal to $V-I+v+\frac{1}{3} b$.
} 
Consider substitutability in implementation first. A high degree of similarity $\Psi$ between non-focal partners benefits $F$ conditional on knowledge sharing because it strengthens $F$ 's bargaining power. However, too much similarity reduces the non-focal partners' incentives to share knowledge, with detrimental effects on $F$ as well. Thus, the optimum level of similarity between non-focal partners from $F$ 's viewpoint is intermediate (Proposition 7, case (iv)).

When substitutability is in rival benefits, these effects are reversed. Partner similarity harms $F$ conditional on knowledge sharing, but also induces the non-focal partners to share knowledge. Initially (for low levels of similarity), knowledge sharing in an alliance portfolio is not sustainable, and $F$ 's payoff is low. However, when $\Psi$ crosses $\Psi^{*}$, knowledge sharing becomes sustainable, so $F^{\prime}$ 's payoff suddenly rises. As $\Psi$ grows further, substitutability in rival benefits monotonically reduces $F$ 's payoff (Proposition 7 , case (i)).

Thus, regardless of which type of substitutability is more important, $F$ is often better off by choosing partners that are neither too similar nor too dissimilar to each other. The relationship between $F$ 's payoff and non-focal partner similarity $\Psi$ has often an inverted-U shape (cases (i) and (iv)).

This basic intuition is complicated by the fact that initial conditions also matter. Depending on the initial propensity of its alliance partners to share knowledge (whether $V-I-\pi_{F}+\frac{2}{3} b \lessgtr 0$ ), only part of the inverted-U curve may be observed. Case (ii) describes a situation where, because substitutability is mostly in rival benefits $\left(\alpha<\frac{1}{2}\right)$ and knowledge sharing can always be sustained, partner similarity is always detrimental to $F$. Hence the optimal value of partner similarity from $F$ 's viewpoint is zero. Case (iii) describes a situation where knowledge sharing can never be sustained. In that case, because there is no knowledge sharing, the degree of partner similarity is inconsequential.

The complexity of these predictions may help explain the variety of often conflicting empirical results. Swaminathan and Moorman (2009) find that alliance announcements create value (i.e., abnormal stock returns) especially when the degree to which the firm's network of alliances involves firms that possess nonredundant knowledge, skills, and capabilities is moderate. Vasudeva and Anand (2011) find an inverted U-shaped relationship between the technological diversity in a focal firm's alliance portfolio and the likelihood that the focal firm cites its partner's patents. Cui and O'Connor (2012) find no statisti- 
cally significant relationship between alliance portfolio resource diversity and innovation, although several interaction effects are significant, while Goerzen and Beamish (2005) and Cui (2013) find monotonic relationships. Our theory can help rationalize these findings; however, further research is surely needed.

\section{Contractual solutions}

Contractual solutions to the hold-up problem have been extensively studied in economics (see Segal and Whinston, 2013, for a survey). In this section, we examine contractual solutions that appear to be important in practice. We argue that, although contracts can facilitate knowledge sharing, their usefulness is often limited.

Payments to share knowledge. A contract specifying payments from the "strong" partner to the "weak" partner to encourage knowledge sharing does not solve the underinvestment problem highlighted in this paper. The reason is that knowledge sharing is not observable by a court. Thus, the weak partner would sign the contract, accept the payment, and then would not share knowledge if that was not in its own interest.

Termination fee contracts. Termination fee contracts may also appear to be a potential solution (Williamson, 1983). However, they will not work in our model.

Suppose collaboration is efficient $(V \geq I)$ but the weak partner will not share knowledge (i.e., $V-\pi_{F}+$ $\left.\pi_{A}<I\right)$. To avoid this problem, suppose $F$ offers a contract to $A$ that pays $x$ to $A$ if the collaboration terminates prematurely, before joint implementation. In this case, once knowledge sharing has occurred, $F$ 's outside option is $\pi_{F}-x$, and $A$ 's outside option is $\pi_{A}+x$. The new gross payoffs that accrue to $F$ and $A$ after negotiations are thus, respectively, $\frac{1}{2}\left(V+\pi_{F}-\pi_{A}\right)-x$ and $\frac{1}{2}\left(V-\pi_{F}+\pi_{A}\right)+x$.

For knowledge sharing to occur, it must be profitable for the weak partner:

$$
\frac{1}{2}\left(V-\pi_{F}+\pi_{A}\right)+x \geq \frac{1}{2} I
$$

However, with a termination fee, the weak partner may behave opportunistically. Specifically, $A$ may not share knowledge simply to force termination and get a payment of $x$. To prevent such behavior, $x$ has to 
be less than $A$ 's payoff from not reneging and sharing knowledge, i.e.,

$$
\begin{aligned}
x & \leq \frac{1}{2}\left(V-\pi_{F}+\pi_{A}\right)+x-\frac{1}{2} I \\
& \Longleftrightarrow\left(V-\pi_{F}+\pi_{A}\right)-I \geq 0 .
\end{aligned}
$$

But (13) cannot hold because we assumed $V-\pi_{F}+\pi_{A}-I<0$. That is, a contract that encourages knowledge sharing also encourages opportunistic behavior by $A$.

Equity alliances. In the model in Section 2, there is no contract specifying how the returns from collaboration are divided. We simply assumed that, given outside options $\left(\pi_{F}, \pi_{A}\right)$, partners split the surplus $V-\left(\pi_{F}+\pi_{A}\right)$ equally among themselves. However, if the partners can commit to a contract that specifies a certain division of the surplus, should they implement their project together, they can improve outcomes. Consider a contract such that, if the partners implement their project together, a share $\lambda \in[0,1]$ of the surplus goes to $A$, and the share $1-\lambda$ of the surplus goes to $F$. The partners' payoffs conditional on knowledge sharing are: ${ }^{24}$

$$
\begin{aligned}
& \Pi_{F}^{E}=\pi_{F}+(1-\lambda)\left[V-\pi_{F}-\pi_{A}\right]-\frac{1}{2} I \\
& \Pi_{A}^{E}=\pi_{A}+\lambda\left[V-\pi_{F}-\pi_{A}\right]-\frac{1}{2} I .
\end{aligned}
$$

Importantly, contract $\lambda$ does not oblige the firms to share knowledge or implement the project together. Instead, $F$ and $A$ can choose between doing so and realizing the payoffs specified under the contract or separating and obtaining their respective outside options. The key assumption we make here is that the partners are unable to renegotiate the contract $\lambda$ in period 2 (after knowledge sharing). If they could do so, then we would expect their (re)negotiation to produce the same outcome as in Section 2, because their ex ante bargaining weights are the same.

Proposition 8 below compares 'equity' alliances associated with contract $\lambda$ to the 'non-equity' alliances where $\lambda=1 / 2$ (that is, the alliances studied in Section 2). We say that knowledge sharing can be

\footnotetext{
${ }^{24}$ An equivalent way of describing the partners' payoffs is to define a contract $\phi$ such that $\Pi_{F}^{E}=(1-\phi) V-\frac{1}{2} I$ and $\Pi_{A}^{E}=\phi V-\frac{1}{2} I$, subject to the constraints that $(1-\phi) V \geq \pi_{F}$ and $\phi V \geq \pi_{A}$. These constraints define upper and lower bounds to $A$ 's equity share $\phi$ which ensure that partners have no incentives to prematurely terminate the alliance after knowledge sharing. The case where $\phi$ reaches its lower bound corresponds to the case where $\lambda=0$, so that all the surplus goes to firm $F$. The case where $\phi$ reaches its upper bound corresponds to the case where all the surplus goes to firm $A$ $(\lambda=1)$.
} 
implemented by an equity alliance if there exists an equity share $\lambda \in[0,1]$ such that both partners are willing to share knowledge. Similarly, we say that knowledge sharing can be implemented by a non-equity alliance if both partners are willing to share knowledge when $\lambda=1 / 2$.

\section{Proposition 8.}

(i). If knowledge sharing can be implemented by a non-equity alliance, then it can also be implemented by an equity alliance. However, the converse is not true.

(ii). If knowledge sharing can be implemented by an equity alliance but not by a non-equity alliance, then $\pi_{F}>\pi_{A}$ implies $\lambda>1 / 2$, and $\pi_{F}<\pi_{A}$ implies $\lambda<1 / 2$.

(iii). Even if knowledge sharing is efficient, knowledge sharing may not be implementable by an equity alliance.

Part (i) is obvious. Non-equity alliances are a special case of equity alliances. Thus, if knowledge sharing can be implemented by a non-equity alliance, it can also be implemented by an equity alliance, but the reverse is not necessarily true.

Part (ii) shows how equity alliances can be structured to facilitate knowledge sharing when non-equity alliances are ineffective. Suppose non-equity alliances are ineffective because knowledge sharing shifts bargaining positions excessively in favor of $F$ (i.e., $\pi_{F}$ is much larger than $\pi_{A}$ ). Then, $F$ may grant the weaker partner $A$ a larger share of the surplus $(\lambda>1 / 2)$ to encourage knowledge sharing. Equity alliances help because they allow partners to flexibly distribute the gains from collaboration. The firm experiencing an adverse shift in bargaining position can be compensated with a greater share of the surplus. The strong partner can commit to a more 'generous' distribution of the surplus (see also Panico 2011 for a related result).

Part (iii), however, shows that, although equity alliances facilitate knowledge sharing, they cannot completely solve the problem. The reason is that shifts in bargaining positions can be large relative to the joint surplus. Partners always retain the option of terminate the alliance at the negotiation stage. Thus, $F$ cannot get less than $\pi_{F}$ and $A$ cannot get less than $\pi_{A}$ at the negotiation stage. But, if $\pi_{F}$ is 
very large, then there may be very little surplus $V-\pi_{F}-\pi_{A}$ to compensate $A$ for sharing knowledge. As a result, knowledge sharing may not be implementable, even if it is socially efficient.

\section{Conclusion}

Firms enter into alliances for a variety of reasons: to facilitate collusion and increase market power (Porter and Fuller, 1986), to share risks and take advantage of new opportunities (Kogut, 1991), to pool resources with other firms (Hennart, 1988) and to acquire new skills and capabilities (Hamel, 1991; Mowery et al., 1996; Khanna et al., 1998).

In this paper, we focus on alliances where an important objective is the acquisition of new skills and capabilities ("learning alliances"), but where contracts are incomplete and firms cannot commit to exploit the newly created knowledge jointly. Firms share knowledge to create value (e.g., new products). However, knowledge sharing also creates appropriability hazards. For instance, a firm may steal a partner's trade secrets, or asymmetric learning may occur. In the latter case, the faster learner may over time be able to reduce its dependency on the partner and appropriate a greater share of the collaborative pie. All these risks, if foreseen, can discourage knowledge sharing, unless contractual or other types of safeguards exist.

Our paper emphasizes commitments that leading firms can make to encourage knowledge sharing. Our theory does not negate the importance of safeguards or knowledge protection; however, it does provide a more nuanced perspective, by incorporating also the incentives of leading firms to create a 'safe space' for collaboration.

The paper has several implications that are relevant to managers and practitioners. A basic but important point is that managers must be aware of their partners' incentives to collaborate. If leading firms do not leave sufficient rents to their alliance partners, the latter will not participate in collaborative endeavours, or will only participate in a perfunctory or opportunistic manner.

Leading firms can build structures to lessen partners' appropriability concerns. These structures sometimes involve "Chinese walls" that compartmentalize and protect partners' confidential information. For instance, Toyota deliberately took steps to separate its operations management consulting division from its purchasing division, so that suppliers would share information with Toyota without worrying 
that this might constrain their future pricing flexibility.

Our theory, by emphasizing the broader theme of commitment to treat partners fairly (and share rents), also highlights the importance of the credibility of such commitments. In the case of Intel Architecture Lab (IAL), credibility was enhanced by the fact that IAL was separated from Intel's other businesses, and that this separation was observable from the outside. This separation, by mitigating competitive threats from Intel's other units, increased complementors' incentives to collaborate with IAL. This approach also provides a different perspective on learning races. Managers should not always try to win the race but should instead sometimes constrain their ability to appropriate value, to encourage collaboration and knowledge sharing.

Alliance portfolio design can also be used to implicitly commit to low levels of appropriation of partners' knowledge, by creating alliance portfolios with desirable characteristics. We show that the simple intuition that alliance portfolios should be constructed to minimize overlaps in technology among partners is potentially misleading because there are types of partner substitutability that may encourage rather than hinder knowledge sharing. Our theory also suggests that managers should select partners that are neither too similar nor too dissimilar to each other, because partner substitutability has opposing effects on value creation and value capture by the focal firm.

Alliances are by definition not zero-sum games. Instead, they have the potential to create value. Value capture strategies must be balanced against the need to ensure value creation. Our focus on the need to induce knowledge sharing by the weaker partner is, at the most abstract level, an attempt put the emphasis back on value creation.

\section{References}

Aghion P, Tirole J. 1994. The management of innovation. Quarterly Journal of Economics 109(4): 1185-1209.

Argote L, McEvily B, Reagans R. 2003. Managing knowledge in organizations: An integrative framework and review of emerging themes. Management Science 49(4): 571-582.

Arora A, Merges RP. 2004. Specialized supply firms, property rights and firm boundaries. Industrial and Corporate Change 13(3): 451-475.

Bae J, Gargiulo M. 2004. Partner substitutability, alliance network structure, and firm profitability in 
the telecommunications industry. Academy of Management Journal 47(6): 843-859.

Baum JA, Calabrese T, Silverman BS. 2000. Don't go it alone: Alliance network composition and startups' performance in Canadian biotechnology. Strategic Management Journal 21(3): 267-294.

Brandenburger A, Stuart H. (2007). Biform games. Management Science 53(4): 537-549.

Christensen CM. 1994. Molding the impossible: The NYPRO/Vistakon disposable contact lens project. Harvard Business School Main Case.

Cohen WM, Nelson RR, Walsh JP. 2000. Protecting their intellectual assets: Appropriability conditions and why US manufacturing firms patent (or not). NBER working paper 7552 .

Cui AS. 2013. Portfolio dynamics and alliance termination: The contingent role of resource dissimilarity. Journal of Marketing 77(3): 15-32.

Cui AS, O'Connor G. 2012. Alliance portfolio resource diversity and firm innovation. Journal of Marketing 76(4): 24-43.

de Fontenay CC, Gans JS. 2005. Vertical integration in the presence of upstream competition. RAND Journal of Economics 36(3): 544-572.

Dussauge P, Garrette B, Mitchell W. 2000. Learning from competing partners: Outcomes and durations of scale and link alliances in Europe, North America and Asia. Strategic Management Journal 21(2) 99-126.

Dyer JH, Nobeoka K. 2000. Creating and managing a high-performance knowledge-sharing network: the Toyota case. Strategic Management Journal 21(3): 345-367.

Fuller MB, Porter ME. 1986. Coalitions and Global Strategy. In Competition in Global Industries, 315-344.

Gawer A, Cusumano MA. 2002. Platform Leadership: How Intel, Microsoft, and Cisco Drive Industry Innovation. Boston, MA: Harvard Business School Press.

Goerzen A, Beamish PW. 2005. The effect of alliance network diversity on multinational enterprise performance. Strategic Management Journal 26(4): 333-354.

Grindley P, Mowery DC, Silverman B. 1994. SEMATECH and collaborative research: Lessons in the design of high-technology consortia. Journal of Policy Analysis and Management 13(4); 723-758.

Grossman SJ, Hart OD. 1986. The costs and benefits of ownership: A theory of vertical and lateral integration. Journal of Political Economy 94(4): 691-719.

Hamel G. 1991. Competition for competence and inter-partner learning within international strategic alliances. Strategic Management Journal 12(Special Issue): 83-103.

Hansen MT. 2002. Knowledge networks: Explaining effective knowledge sharing in multiunit companies. Organization Science 13(3): 232-248.

Hart O, Moore J. 1990. Property rights and the nature of the firm. Journal of Political Economy 98(6): 1119-1158.

Hennart J-F. 1988. A transaction cost theory of equity joint ventures. Strategic Management Journal 9(4): $361-374$. 
Hennart J-F, Roehl T, Zietlow D. 1999. 'Trojan Horse' or 'workhorse'? The evolution of U.S.-Japanese joint ventures in the United States. Strategic Management Journal 20(1): 15-29.

Herbst P, Walz U. 2017. The design of vertical R\&D collaborations. Economica 84(333): 54-77.

Iansiti M, Levien R. 2004. The keystone advantage: What the new dynamics of business ecosystems mean for strategy, innovation, and sustainability. Harvard Business Press.

Inkpen AC. 2000. A note on the dynamics of learning alliances: Competition, cooperation, and relative scope. Strategic Management Journal 21(7): 775-779.

Inkpen AC. 2002. Learning, knowledge management, and strategic alliances: So many studies, so many unanswered questions. In Cooperative Strategies and Alliances, Contractor FJ, Lorange P (eds). Elsevier Science: Oxford, U.K.: 267-289.

Inkpen AC. 2005. Learning Through Alliances: General Motors and NUMMI. California Management Review 47(4): 114-136.

Inkpen AC, Beamish PW. 1997. Knowledge, bargaining power, and the instability of international joint ventures. Academy of Management Review 22(1): 177-202.

Katila R, Rosenberger JD, Eisenhardt KM. 2008. Swimming with sharks: Technology ventures, defense mechanisms and corporate relationships. Administrative Science Quarterly 53(2): 295-332.

Khanna T, Gulati R, Nohria N. 1998. The dynamics of learning alliances: Competition, cooperation, and relative scope. Strategic Management Journal 19(3): 193-210.

Kogut B. 1991. Joint ventures and the option to expand and acquire. Management Science 37(1): 19-33.

Lavie D. 2007. Alliance portfolios and firm performance: A study of value creation and appropriation in the US software industry. Strategic Management Journal 28(12): 1187-1212.

McEvily SK, Das S, McCabe K. 2000. Avoiding competence substitution through knowledge sharing. Academy of Management Review 25(2): 294-311.

Mitchell W, Singh K. 1996. Survival of businesses using collaborative relationships to commercialize complex goods. Strategic Management Journal 17(3): 169-195.

Morgan J, Várdy F. 2013. The fragility of commitment. Management Science 59(6): 1344-1353.

Mowery DC, Oxley JE, Silverman BS. 1996. Strategic alliances and interfirm knowledge transfer. Strategic Management Journal 17( Special Issue): 77-91.

Mowery DC, Oxley JE, Silverman BS. 2002. The two faces of partner-specific absorptive capacity: Learning and cospecialization in strategic alliances. In Cooperative Strategies and Alliances, Contractor FJ, Lorange P (eds). Elsevier Science: Oxford, U.K.: 291-319.

Oxley JE. 1997. Appropriability hazards and governance in strategic alliances: A transaction cost approach. Journal of Law, Economics, ES Organization 13(2): 387-409.

Oxley J, Wada T. 2009. Alliance structure and the scope of knowledge transfer: Evidence from U.S.-Japan agreements. Management Science 55(4): 635-649.

Panico C. 2011. On the contractual governance of research collaborations: Allocating control and intellectual property rights in the shadow of potential termination. Research Policy 40(10): 1403-1411. 
Panico C. 2017. Strategic interaction in alliances. Strategic Management Journal 38(8): 1646-1667.

Patacconi A, Vikander N. 2015. The asymmetric fundamental transformation. Working paper available at https://papers.ssrn.com/sol3/papers.cfm?abstract_id=2737509.

Pisano GP. 1989. Using equity participation to support exchange: Evidence from the biotechnology industry. Journal of Law, Economics \& Organization 5(1): 109-126.

Reagans R, McEvily B. 2003. Network structure and knowledge transfer: The effects of cohesion and range. Administrative Science Quarterly 48(2): 240-267.

Ryall MD, Sorenson O. 2007. Brokers and competitive advantage. Management Science 53(4): 566-583.

Schelling T. 1960. The Strategy of Conflict. Cambridge, MA: Harvard University Press.

Segal I, Whinston MD. 2013. Property rights. In Gibbons R, Roberts J, (Eds.), Handbook of Organizational Economics, Princeton University Press, NJ; 100-158.

Steinhilber S. 2013. Strategic Alliances: Three ways to make them work. Harvard Business Press, Boston MA.

Swaminathan V, Moorman C. 2009. Marketing alliances, firm networks, and firm value creation. Journal of Marketing 73(5): 52-69.

Vasudeva G, Anand J. 2011. Unpacking absorptive capacity: A study of knowledge utilization from alliance portfolios. Academy of Management Journal 54(3): 611-623.

Veugelers R, Kesteloot K. 1994. On the design of stable joint ventures. European Economic Review 38(9): 1799-1815.

Veugelers R, Kesteloot K. 1996. Bargained shares in joint ventures among asymmetric partners: Is the Matthew effect catalyzing? Journal of Economics 64(1): 23-51.

Wassmer U, Dussauge P. 2011. Network resource stocks and flows: How do alliance portfolios affect the value of new alliance formations? Strategic Management Journal, 32: 871-883.

Williamson OE. 1975. Markets and Hierarchies. The Free Press, New York.

Williamson OE. 1983. Credible commitments: Using hostages to support exchange. American Economic Review 73(4): 519-540.

Yan A, Gray B. 1994. Bargaining power, management control, and performance in United States-China joint ventures: A comparative case study. Academy of Management Journal 37(6): 1478-1517.

Zeng M, Hennart JMA. 2002. From learning races to cooperative specialization: Towards a new framework for alliance management. In Cooperative Strategies and Alliances, Contractor FJ, Lorange P (eds). Elsevier Science: Oxford, U.K.: 189-210. 